
8
Research Square
Preprints are preliminary reports that have not undergone peer review.
They should not be considered conclusive, used to inform clinical practice, or referenced by the media as validated information.

\title{
Associations of Body Mass Index, Visceral Fat Area, Waist Circumference, and Waist-To-Hip Ratio with Cognitive Function in Western China: Results from A WCHAT Study
}

\author{
Xiaolei Liu \\ West China Hospital of Sichuan University \\ Xiaoyan Chen \\ Zigong Mental Health Center \\ Lisha Hou \\ West China Hospital of Sichuan University \\ Xin Xia \\ West China Hospital of Sichuan University \\ Fengjuan $\mathrm{Hu}$ \\ West China Hospital of Sichuan University \\ Shuyue Luo \\ West China Hospital of Sichuan University \\ Wanyu Zhao \\ West China Hospital of Sichuan University \\ Yan Zhang \\ West China Hospital of Sichuan University \\ Meiling Ge \\ West China Hospital of Sichuan University \\ Gongchang Zhang \\ West China Hospital of Sichuan University \\ Birong Dong ( $\sim$ birongdong123@outlook.com ) \\ West China Hospital of Sichuan University
}

\section{Research Article}

Keywords: BMI, VFA, WHR, WC, cognitive function

Posted Date: February 3rd, 2021

DOl: https://doi.org/10.21203/rs.3.rs-154197/v1

License: (c) (1) This work is licensed under a Creative Commons Attribution 4.0 International License. Read Full License 


\section{Abstract}

\section{Objectives}

This study examined the relationship between cognitive performance and obesity parameters, such as body mass index (BMI), visceral fat area (VFA), waist circumference (WC), and waist-to-hip ratio (WHR) in western China.

\section{Study design}

A cross-sectional study

\section{Methods}

3914 participants, aged $>50$ years, were recruited in this study. Anthropometrics measurements, life-style factors, chronic disease comorbidities, and sleep qualities were recorded for each participant. Among the anthropometrics, BMP, WC, and WHR were assessed using standard procedures, while VHA was calculated using bioelectrical impedance analysis. Cognitive performance was estimated using the Short Portable Mental Status Questionnaire (SPMSQ). Finally, relationships between cognitive abilities and BMI, VFA, WC, and WHR were evaluated using univariate and multivariate regression analyses.

\section{Results}

Cognitive decline (CD) occurred at a rate of $13.29 \%$ among the 3914 participants. A strong correlation was observed between cognitive abilities and BMI of male patients aged 50-59 yrs (OR 1.116,95\% Cl1.002-1.242), in the adjusted model. Alternately, WHR was shown to be significantly related to CD in females aged $>70$ years (OR $0.041,95 \%$ Cl0.002-0.671). WC was shown to have a strong association with CD in males (OR 1.023,95\% Cl1.003-1.024). Lastly, WHR was closely connected to CD in participants with $\mathrm{BMI}<25 \mathrm{~kg} / \mathrm{m}^{2}$ (OR $\left.0.022,95 \% \mathrm{Cl} 0.002-0.209\right)$.

\section{Conclusions}

Our findings suggest that a higher middle age BMI is associated with $\mathrm{CD}$, whereas, in the elderly population, a higher WHR is related to improved cognitive performance. Further investigation is warranted to elucidate a relationship between VFA and CD.

\section{Background}

Obesity, or excessive body fat, is one of the leading disease conditions in the world today. Several studies have demonstrated a positive association between obesity and dementia or cognitive decline (CD). However, the impact of obesity markers, such as body mass index (BMI), visceral fat area (VFA), waist circumference (WC) and waist-to-hip ratio (WHR), in patients without dementia remains unclear. Among the obesity markers, BMI is considered the most common risk factor for dementia. However, the evidences for this are controversial. Several studies have suggested that a higher middle age BMI can significantly increase the risk for dementia ${ }^{1,2}$. Conversely, in another study, BMI was discovered to have a U-shaped relationship with dementia. Therefore, in patients $<76$ year old, a high BMI increased dementia risk, whereas, in patients $>76$ year old, high BMI reduced dementia risk ${ }^{3}$. Moreover, several longitudinal studies demonstrated that in adulthood, excessive body fat augmented risk of CD later in life $e^{4-6}$.

The evidences concerning the relationship between VFA and cognitive abilities are also conflicting. In one study, increased visceral adiposity was associated with poor cognitive performance in subjects $<70$ year old ${ }^{7}$. Likewise, in 
another study, excessive VFA was shown to worse cognitive abilities in young adults ${ }^{8}$. Conversely, a recent study demonstrated that a high VHA is closely correlated with a low risk of non-amnestic mild cognitive impairement ( $\mathrm{MCl}$ ) in women, suggesting visceral fat may partially protect against $C D^{9}$. Alternately, in a study of type 2 diabetes (T2D) patients, it was proposed that the impaired endothelium-independent vascular smooth muscle reactivity may mediate the relationship between elevated visceral adiposity and reduced cognitive performance ${ }^{10}$.

In terms of WHR, researchers discovered an association with cognitive impairment, which may be a result of neurodegenerative, vascular, or metabolic processes that modulate brain structures ${ }^{11}$. Likewise, a longitudinal study demonstrated that both WHR and WC can predict a nearly two-fold decrease in cognitive performance in T2D participants within $2 \mathrm{yrs}^{12}$. Conversely, in another report, WHR was shown to be related to slower cognitive decline in elderly patients, indicating cognitive protection associated with higher WHR in the elderly ${ }^{13}$.

In this study, we collected cross-sectional data from the West-China Health and Aging Trend (WCHAT) study, involving a multi-ethnic cohort study in western China, to assess the relationship between adiposity parameterss (such as, BMI, VFA, WHR, and WC) and CD.

\section{Methods}

This cross-sectional study collected data from the WCHAT study, which examined the relationship between geriatrics syndromes and lifestyle of people in western China, such as diet, alcohol consumption, and smoking, and so on ${ }^{14-16}$. The WCHAT study received approval from the Ethical Review Committee (reference: 2017-445) in the West China Hospital, Sichuan University, Chengdu, China. 4 independent interviewers were involved in data assembly from 4 western China provinces, namely, Yunnan, Guizhou, Sichuan, and Xinjiang.

\section{Study participants}

The study participants, aged $>50 \mathrm{yr}$ old, were selected by the local government and provided verbal and written consent to their participation in the study. The WCHAT study, which provided us the data for this study, included 7,536 participants aged $\geq 50 \mathrm{yr}$ old from over 18 ethnic populations among 4 western China provinces; Sichuan, Yunnan, Guizhou, and Xinjiang. Among them, 4,500 participants with bioimpedance data, measured using Inbody 770 , were selected for the study. Among these participants, those with stroke (62), mental illness (5), participants missing cognitive function assessment (239), and participants belonging to a small ethnic group (280) were excluded from the study, resulting in a total of 3,914 participants included in this study.

\section{Demographic, anthropometric, and life styles data collection}

The baseline demographic information included age, gender, marital status, educational level, ethnic background, occupation, fertility condition, and hearing ability. The lifestyle variables included tea-drinking, alcohol drinking, smoking, and sleep quality. The anthropometric data included height, weight, BMI, WC, WHR, and VFA. WHR was measured twice by volunteers and the average data was used in the analysis. To calculate WC, measurement was taken at the midpoint between the iliac crest and lower rib at the end of a normal expiration. The hip circumference was measured at the maximum circumference over the buttocks below the iliac crest. WHR was calculated as the ratio of WC to hip circumference. Weight measurement was performed using a digital scale and height was calculated using a stadiometer. The BMI was calculated as the weight over height squared. VFA was assessed using bioimpedance analysis with the help of Inbody 770 (BioSpace, Seoul, Korea) ${ }^{17-19}$.

\section{Assessment of cognitive decline, depression, sleep quality, and chronic diseases.}


Cognitive performance was assessed according to the questions on the Short Portable Mental Status Questionnaire (SPMSQ). A high SPMSQ score denoted poor cognitive ability. In particular, a score of 0-2 represented good cognitive performance, a score of 3-4 indicated $\mathrm{MCl}$, a score of 5-7 meant moderate cognitive impairment, and lastly, a score of 8-10 indicated severe cognitive impairement or $C D^{20}$. In addition, depression was evaluated using a 15 question Geriatric Depression Scale (GDS-15) ${ }^{21}$ with yes/no answers. The GDS-15 is a universally used questionnaire for the detection of depression. Sleep quality was evaluated using the widely used sleep assessment tool, Pittsburgh Sleep Quality Index (PSQI), where scores $>5$ were indicative of poor self-reported sleep quality ${ }^{22}$. Lastly, a self-reported medical history of chronic diseases was taken from each participant. Chronic diseases included hypertension, osteoarticular disease, lung disease, diabetes mellitus, and so on and comorbidities was defined as having two or more chronic diseases.

\section{Statistical analysis}

The obesity threshold was set as follows: $\mathrm{BMI} \geq 25.0 \mathrm{~kg} / \mathrm{m}^{2}$ (World Health Organization) ${ }^{23}$, WHR: 0.90 in men and 0.85 in women (Asian modified WHO criteria for metabolic syndrome) ${ }^{24}$, WC $>90 \mathrm{~cm}$ for men and $>80 \mathrm{~cm}$ for women (Asian modified The National Cholesterol Education Program) ${ }^{24}$, VFA $\geq 100 \mathrm{~cm}^{2}$ (published literature) ${ }^{25-27}$.

The normality of variables was assessed using $\mathrm{R}$ version 3.6.1. The participants were assigned to one of two groups: complete cognitive function (CCF) or CD. Our findings are expressed as mean \pm standard deviation (SD). Statistical significance ( $p<0.05$, two sided) was assessed with student's $t$-test (comparing 2 different groups) and the count data is represented as a percentage, using the $\chi 2$ test.

As this study explored the associations between cognitive performance and obesity variables like BMI, VFA, WC, and WHR, we established both univariate and multivariate regression models with BMI, VFA, WC, and WHR as the independent variables and cognitive performance as the dependent variable. The multivariate models were next adjusted according to BMI, VFA, WC, and WHR to produce fully adjusted cognitive results.

\section{Results}

\section{Characteristics of the study participants}

3,914 participants, aged $\geq 50$ yrs were included in this study. The incidence of CD among the selected participants was $13.29 \%$. A breakdown of their age groups showed that $<60,60-69,70-79$ and $\geq 80$ had a CD prevalence of $10.23 \%, 11.79 \%, 20.65 \%$, and $33.03 \%$, respectively, suggesting an increase in CD with age. Among the different ethnic populations, CD was distributed as follows: Han, Zang, and Qiang exhibited $9.52 \%, 17.66 \%$, and $15.25 \%$ of CD respectively. A summary of data, including the clinical and sociodemographic, anthropometric, sleeping quality, lifestyle factors, depression, and chronic diseases comorbidity are provided in Table 1. Based on our analysis, participants with CD were, on average, older females who were missing a significant other, were of low educational background, worked as laborer, drank less tea and alcohol, smoked less, had multiple children, had impaired hearing, high GDS-15 score, high WC, and low WHR, as compared to participants without CD (Table 1). We also demonstrated that sleep quality and chronic disease comorbidities had a negative effect on CD. However, VFA and BMI were not significantly altered between the CCF and the CD groups (Table 1). 
Table 1

Basic characteristics of study participates $(n=3914)$.

\section{Complete cognitive function}

$$
N=3394(86.71 \%)
$$

Ethnic groups

Han

Zang

Qiang

Age groups

$<60$

60-69

70-79

$\geq 80$

Gender

male

female

Marriage status

With spouse

Without spouse

Smoking history

Yes

No

Drinking history

Yes

No

Tea drinking

Yes

No

Education level

Primary school and below

Middle school and above

\begin{tabular}{|l}
\hline $1635(90.48 \%)$ \\
\hline $909(82.34 \%)$ \\
\hline $850(84.75 \%)$
\end{tabular}

1421(89.77\%)

1377(88.21\%)

515(79.35\%)

$81(66.94 \%)$

2096(83.77\%)

2905(88.08\%)

489(79.38\%)

610(92.71\%)

2784(85.51\%

890(90.17\%)

2504(85.55\%)

$1713(88.44 \%)$

1681(85.03\%)

2054(83.06\%)

1340(92.99\%)
1298(91.93\%)
Cognitive decline

$P$ value

$N=520(13.29 \%)$

$<.0 .01$

172(9.52\%)

$195(17.66 \%)$

$153(15.25 \%)$

$<.0 .01$

162(10.23\%)

184(11.79\%)

134(20.65\%)

40(33.03\%)

$$
<.0 .01
$$

114(8.07\%)

406(16.23\%)

$$
<.0 .01
$$

393(11.92\%)

$127(20.62 \%)$

$<0.01$

48(7.29\%)

472(14.49\%)

97(9.83\%)

$423(14.45 \%$

$<.0 .01$

224(11.56)

296(14.97\%)

$$
<.0 .01
$$

419(16.94\%)

101(7.01\%)

Data are shown using \% or mean (standard deviation). $P$ values were calculated with chi-squared tests and oneway analysis of variance (ANOVA) for categorical and continuous variables, respectively. BMI, body mass index; WC, waist circumference; WHR, waist hip ratio; VFA, visceral fat area. 
Complete cognitive function

Occupation

Physical labor

Brain work

Fertility status

Yes

No

Chronic disease comorbidity

Yes

No

Hearing ability

Complete

Impaired

Sleeping quality

Good

Bad

WC

$M \leq 90, F \leq 80$

$M \leq 90, F \leq 80$

WHR

$M \geq 0.9, F \geq 0.85$

$M<0.9, F<0.85$

VFA

$\geq 100$

$<100$

BMI

$\mathrm{BMl}<18.5$

$18.5 \leq \mathrm{BMI}<25$

$25 \leq \mathrm{BMI}$

GDS-15 score
2885(85.63\%)

509(93.39\%)

2077(84.06\%)

1317(91.27\%)

$376(84.11 \%)$

3018(87.05\%)

2696(88.98\%)

$698(78.96 \%)$

1666(86.05\%)

1563(87.76\%)

$87.22 \pm 10.72$

2490(87.15\%)

904(85.53\%)

$0.92 \pm 0.08$

2490(87.15\%)

904(85.53\%)

$107.45 \pm 40.42$

1841(86.23\%)

1553(87.30\%)

$25.38 \pm 3.68$

62(82.67\%)

1538(86.65\%)

1722(86.66\%)

$2.45 \pm 2.23$
Cognitive decline

$P$ value

$<.0 .01$

484(14.37\%)

$36(6.61 \%)$

$<.0 .01$

394(15.94\%)

126(8.73\%)

0.108

71(15.89\%)

449(12.95\%)

$<0.01$

334(11.02\%)

186(21.04\%)

0.123

270(13.95\%)

$218(12.24 \%$

$88.31 \pm 11.24$

0.035

367(12.85)

$<0.01$

153(14.47\%)

$0.90 \pm 0.09$

$<0.01$

367(12.85\%)

0.193

153(14.47\%)

$111.01 \pm 44.94$

0.089

294(13.77\%)

0.326

$226(12.70 \%)$

$25.52 \pm 4.67$

0.532

13(17.33\%)

0.684

237(13.35\%)

265(13.34\%)

$3.73 \pm 2.72$

$<0.01$

Data are shown using \% or mean (standard deviation). $P$ values were calculated with chi-squared tests and oneway analysis of variance (ANOVA) for categorical and continuous variables, respectively. BMI, body mass index; WC, waist circumference; WHR, waist hip ratio; VFA, visceral fat area. 
The univariate and multivariate analyses of CD using variables like BMI, VFA, WHR and WC in 50 yrs old males and females are summarized in Table 2. WHR was shown to be strongly related to CD in females using both univariate (OR $0.221,95 \% \mathrm{Cl} 0.057-0.854$ )and multivariate (OR $0.135,95 \% \mathrm{Cl} 0.032-0.581$ ) analysis. Alternately, in males, both univariate (OR 1.020,95\% Cl1.001-1.039凶 and multivariate (OR 1.023,95\% Cl1.003-1.024) analysis revealed WC to be closely related to $\mathrm{CD}$.

Table 2

Results of univariate and multivariate analyses of BMI, VFA, WHR, WC and cognitive decline in male and female, respectively $(n=3914)$.

\begin{tabular}{|c|c|c|c|c|c|c|c|c|}
\hline \multicolumn{9}{|c|}{ Unadjusted model } \\
\hline & \multicolumn{2}{|l|}{ BMI } & \multicolumn{2}{|l|}{ VFA } & \multicolumn{2}{|l|}{ WHR } & \multicolumn{2}{|l|}{ WC } \\
\hline & OR(95\% Cl) & $\begin{array}{l}\mathrm{P}- \\
\text { value }\end{array}$ & OR(95\% Cl) & $\begin{array}{l}P- \\
\text { value }\end{array}$ & OR(95\% Cl) & $\begin{array}{l}P- \\
\text { value }\end{array}$ & OR(95\% Cl) & P-value \\
\hline \multirow[t]{2}{*}{ M } & 0.963 & 0.169 & 0.997 & 0.233 & 0.108 & 0.062 & 1.020 & 0.034 \\
\hline & $\begin{array}{l}(0.912- \\
1.016)\end{array}$ & & $\begin{array}{l}(0.991- \\
1.002)\end{array}$ & & $(0.01-1.117)$ & & $\begin{array}{l}(1.001- \\
1.039)\end{array}$ & \\
\hline \multirow[t]{2}{*}{$\mathrm{F}$} & 1.015 & 0.257 & 1.000 & 0.723 & 0.221 & 0.029 & 1.002 & 0.623 \\
\hline & $\begin{array}{l}(0.989- \\
1.043)\end{array}$ & & $\begin{array}{l}(0.998- \\
1.003)\end{array}$ & & $\begin{array}{l}(0.057- \\
0.854)\end{array}$ & & $\begin{array}{l}(0.993- \\
1.012)\end{array}$ & \\
\hline \multicolumn{9}{|c|}{ Adjusted model } \\
\hline & BMI & & VFA & & WHR & & WC & \\
\hline & OR(95\% Cl) & $\begin{array}{l}\mathrm{P}- \\
\text { value }\end{array}$ & OR(95\% Cl) & $\begin{array}{l}\mathrm{P}- \\
\text { value }\end{array}$ & OR(95\% Cl) & $\begin{array}{l}\mathrm{P} \text { - } \\
\text { value }\end{array}$ & OR(95\% Cl) & P-value \\
\hline \multirow[t]{2}{*}{ M } & 0.984 & 0.588 & 0.998 & 0.486 & 0.206 & 0.234 & 1.023 & 0.024 \\
\hline & $\begin{array}{l}(0.928- \\
1.043)\end{array}$ & & $\begin{array}{l}(0.992- \\
1.004)\end{array}$ & & $\begin{array}{l}(0.015- \\
2.769)\end{array}$ & & $\begin{array}{l}(1.003- \\
1.044)\end{array}$ & \\
\hline \multirow[t]{2}{*}{$F$} & 1.026 & 0.073 & 1.002 & 0.212 & 0.135 & 0.007 & 1.002 & 0.675 \\
\hline & $\begin{array}{l}(0.998- \\
1.056)\end{array}$ & & $\begin{array}{l}(0.999- \\
1.005)\end{array}$ & & $\begin{array}{l}(0.032- \\
0.581)\end{array}$ & & $\begin{array}{l}(0.992- \\
1.013)\end{array}$ & \\
\hline
\end{tabular}

In Table 3, we introduced an age stratification. Based on our analysis, BMI was found to be significantly associated with CD in males aged 50-59 yrs (OR 1.116,95\% Cl1.002-1.242). On the other hand, WHR was closely related to CD in females aged $\geq 70$ yrs (OR 0.041, 95\% Cl0.002-0.671). 
Table 3

Multivariate analyses of BMI, VFA, WHR, WC and cognitive decline in male and female in different age groups, respectively $(n=3914)$.

\begin{tabular}{|c|c|c|c|c|c|c|c|c|c|}
\hline & & BMI & & VFA & & WHR & & WC & \\
\hline & & OR(95\% Cl) & $\begin{array}{l}\mathrm{P}- \\
\text { value }\end{array}$ & OR(95\% Cl) & $\begin{array}{l}P \text { - } \\
\text { value }\end{array}$ & $\mathrm{OR}(95 \% \mathrm{Cl})$ & $\begin{array}{l}P \text { - } \\
\text { value }\end{array}$ & OR(95\% Cl) & $\begin{array}{l}\mathrm{P} \text { - } \\
\text { value }\end{array}$ \\
\hline \multirow[t]{2}{*}{$\begin{array}{l}50- \\
59\end{array}$} & $M$ & $\begin{array}{l}1.116(1.002- \\
1.242)\end{array}$ & 0.047 & $\begin{array}{l}1.005(0.995- \\
1.016)\end{array}$ & 0.308 & $\begin{array}{l}32.26(0.133- \\
7811.27)\end{array}$ & 0.215 & $\begin{array}{l}1.035(0.995- \\
1.078)\end{array}$ & 0.089 \\
\hline & $\mathrm{F}$ & $\begin{array}{l}1.005(0.957- \\
1.055)\end{array}$ & 0.855 & $\begin{array}{l}1.002(0.997- \\
1.007)\end{array}$ & 0.41 & $\begin{array}{l}0.172(0.013- \\
2.242)\end{array}$ & 0.179 & $\begin{array}{l}1.000(0.983- \\
1.018)\end{array}$ & 0.970 \\
\hline \multirow[t]{2}{*}{$\begin{array}{l}60- \\
69\end{array}$} & M & $\begin{array}{l}0.970(0.873- \\
1.078)\end{array}$ & 0.571 & $\begin{array}{l}0.995(0.985- \\
1.005)\end{array}$ & 0.325 & $\begin{array}{l}0.034(0- \\
3.688)\end{array}$ & 0.157 & $\begin{array}{l}1.003(0.969- \\
1.039)\end{array}$ & 0.855 \\
\hline & $\mathrm{F}$ & $\begin{array}{l}1.031(0.978- \\
1.087)\end{array}$ & 0.259 & $\begin{array}{l}1.003(0.998- \\
1.008)\end{array}$ & 0.193 & $\begin{array}{l}0.254(0.017- \\
3.741)\end{array}$ & 0.318 & $\begin{array}{l}1.006(0.989- \\
1.022)\end{array}$ & 0.517 \\
\hline \multirow[t]{2}{*}{$\gtreqless$} & $M$ & $\begin{array}{l}0.916(0.825- \\
1.016)\end{array}$ & 0.097 & $\begin{array}{l}0.998(0.987- \\
1.008)\end{array}$ & 0.676 & $\begin{array}{l}0.006(0- \\
1.387)\end{array}$ & 0.065 & $\begin{array}{l}1.03(0.999- \\
1.063)\end{array}$ & 0.060 \\
\hline & $\mathrm{F}$ & $\begin{array}{l}1.045(0.993- \\
1.099)\end{array}$ & 0.091 & $\begin{array}{l}1(0.994- \\
1.006)\end{array}$ & 0.990 & $\begin{array}{l}0.041(0.002- \\
0.671)\end{array}$ & 0.025 & $\begin{array}{l}1.005(0.981- \\
1.03)\end{array}$ & 0.691 \\
\hline \multicolumn{10}{|c|}{$\begin{array}{l}\text { M, male; F, Female; BMI, body mass index; WC, waist circumference; WHR, waist hip ratio; VFA, visceral fat area. } \\
\text { The multivariate analysis was adjusted for ethnic groups, marriage status, education level, occupation and life- } \\
\text { style factors (smoking, drinking alcohol and tea), sleeping quality, fertility status, chronic disease comorbidities, } \\
\text { depression status. BMI, VFA, WHR and WC were all analyzed as continuous variable. }\end{array}$} \\
\hline
\end{tabular}

Table 4 illustrates the multivariate analysis of CD verses VFA, WHR, WC, and BMI. We demonstrated that WHR significantly accelerates $\mathrm{CD}$ in participants with $\mathrm{BMI}<25 \mathrm{~kg} / \mathrm{m}^{2}$ (OR 0.022, 95\% CI0.002-0.209). 
Table 4

Association of WHR, VFA and WC with cognitive decline under different BMI groups.

\begin{tabular}{|c|c|c|}
\hline & $8.5 \leq \mathrm{BMK}<25$ & $\mathrm{BMI} \geq 25$ \\
\hline & $N=1775$ & $N=1987$ \\
\hline \multicolumn{3}{|l|}{ WHR } \\
\hline rang & $0.29-2.59$ & $0.31-1.55$ \\
\hline Mean & $0.89 \pm 0.08$ & $0.94 \pm 0.07$ \\
\hline $\mathrm{OR}, 95 \% \mathrm{Cl}$ & $0.022(0.002-0.209){ }^{* *}$ & $0.204(0.034-1.211)$ \\
\hline \multicolumn{3}{|l|}{ Waist } \\
\hline rang & $58.50-146.00$ & $46.60-140.00$ \\
\hline Mean & $87.30 \pm 10.22$ & $87.76 \pm 10.35$ \\
\hline $\mathrm{OR}, 95 \% \mathrm{Cl}$ & $1.006(0.991-26.15)$ & $1.005(0.992-1.018)$ \\
\hline \multicolumn{3}{|l|}{ VFA } \\
\hline rang & $23.90-224.30$ & $33.00-263.40$ \\
\hline Mean & $81.66 \pm 26.15$ & $133.63 \pm 34.75$ \\
\hline $\mathrm{OR}, 95 \% \mathrm{Cl}$ & $1(0.994-1.006)$ & $1.002(0.998-1.007)$ \\
\hline \multicolumn{3}{|c|}{$\begin{array}{l}\text { Multivariate analyses of VFA, WHR, WC and cognitive decline under different BMI groups. The multivariate } \\
\text { analysis was adjusted for age, gender, ethnic groups, marriage status, education level, occupation and life-style } \\
\text { factors (smoking, drinking alcohol and tea), sleeping quality, fertility status, chronic disease comorbidities, } \\
\text { depression status. BMI, VFA, WHR and WC were all analyzed as continuous variable. ** } p<0.01 \text {. }\end{array}$} \\
\hline
\end{tabular}

\section{Discussion}

We performed a large cohort cross-sectional study to investigate the relationship between obesity and CD. Among the 3,914 participants examined in this paper, $13.29 \%$ exhibited CD, which increased with age. This is consistent with other studies that reported a close link between aging and CD. In a recent meta-analysis study $(n=80$ studies), the prevalence of CD ranged between $5.1 \%$ and $41 \%$ with a median of $19.0 \%{ }^{28}$. In a separate global study, dementia was shown to affect an estimated $1.8 \%$ of people in their $60 \mathrm{~s}, 5.1 \%$ of people in their $70 \mathrm{~s}, 15.1 \%$ of people in their 80 s, and $35.7 \%$ of people in their $90 \mathrm{~s}^{29}$. Multiple factors are involved in the cognitive dysfunction, including inflammation, insulin resistance, stroke, oxidation and stress, virus infection, and so on ${ }^{30}$.

In this study, obesity was evaluated by BMI, VFA, WHR, and WC. According to our results, not all obesity indicators were involved in promoting CD. BMI, for instance, accelerated CD in people aged 50-59 yrs. However, with increasing age, particularly, $\geq 60$ year, BMI failed to produce a strong effect on CD. This result also corroborates findings from other researchers that demonstrated high $\mathrm{BMI}$ in middle age, but not in elderly, contributed to $\mathrm{CD}^{1,4}$. It is yet unclear whether the lack of effect of BMI on CD in later life is accurate or whether a high BMI in elderly is truly protective of cognitive function. To better understand this relationship in later life, further longitudinal studies are warranted.

We also discovered that WHR is positively associated with CD among the elderly population. So, a high WHR was related to a slower $C D$ among $\geq 70$ yrs olds. This finding, along with our elderly BMI data, suggests that adiposity 
may have a protective effect on cognitive function. In fact, there are a few reports on possible mechanisms of this adipose-cognition relationship ${ }^{13}$. One study, for instance, proposed that estrogen connects excess adipose tissue to improved cognition in the elderly. Elders with more fat cells often have high estrogen levels, due to the peripheral androgen conversion to estrogens, and estrogen is beneficial for cognitive function ${ }^{31}$. In another study, leptin, which is elevated in obese individuals, was suggested to play a role due to its neuprotective nature ${ }^{32}$. Indeed, in the Framingham Study, increased leptin levels were shown to be associated with decreased dementia ${ }^{33}$. Interestingly, we observed a strong negative association between WHR and CD risk in participants with normal BMI in the fully adjusted model. This indicated that WHR might protect against CD in people with normal BMI. Our WHR findings do not corroborate others findings ${ }^{34}$ where they showed a positive correlation between WHR and CD risk among elderly with $\mathrm{BMI}>25.3 \mathrm{~kg} / \mathrm{m}^{2}$. Further investigation into this relationship is necessary to understand the complicated nature of WHR regulating CD.

Based on our results, WC was significantly associated with CD in males. But, once we adjusted for age, the relationship was no longer significant. This may be because age attenuated this relationship. Higher WC is normally indicative of central obesity, which is a known risk factor for CD. One study demonstrated that excessive fat mass, measured by WC and adjusted for BMI, was closely related to increased risk of $C D^{35}$. However, in this study, we did not observe any significant association between WC and CD under any BMI groups. There is more work to be done before a consensus is reached regarding the relationship between WC and CD.

Lastly, our analysis did not show any significant correlation between VFA and CD in the adjusted and unadjusted models. It may be due to our use of the BIA method, instead of CT or MRI which is far more accurate. There are limited studies on the relationship between VFA and CD. One study demonstrated that high VFA quartiles in women were associated with a low risk of non-amnestic $\mathrm{MCl}^{9}$. Similarly, another study revealed an inverse relationship between VFA and delayed memory and language scores in $T 2 D^{36}$. Further longitudinal studies are warranted for a better understanding of the relationship between VFA and CD.

\section{Limitations}

This was a large-population study. As such, caution must be taken in adjusting for essential confounders that might be associated with the study, such as dietary intake. Moreover, this study was primarily observational. A causal relationship between obesity and CD must be explored in future investigations. Lastly, those who volunteered to participate in this study were relatively young and healthy, which may have introduced bias in our results.

\section{Conclusions}

Our findings suggest that a high BMI increases the probability of CD in middle aged men. Alternately, increased WHR increased CD risk in elderly women and in individuals with normal BMI. Lastly, our study has not reached a general consensus regarding the relationship between CD and WC or VFA and further investigation is necessary in this regard.

\section{Declarations}

\section{Acknowledgements}

We thank all the volunteers for the participation and personnel for their contribution to the WCHAT study.

\section{Funding}

Page $10 / 13$ 
This work was supported by National Clinical Research Center for Geriatrics (Z2018B09), the Fundamental Research Funds for the Central Universities (20826041D4046), Post-doc Epidemic Prevention and Control Program (0040204153349), West China Hospital Post-doc Program (2020HXBH011).

\section{Ethical Statement}

Informed consent was provided by each participant or their proxy respondents before

participating in the study. The study was approved by the Ethics Committee of Sichuan University (reference: 2017445). All the experiment protocol for involving human data was in accordance to guidelines of national/international/institutional or Declaration of Helsinki in the manuscript.

\section{Conflicts of Interest}

The authors report no conflicts of interest in this work.

\section{Contributor}

Xiaolei Liu and Xiaoyan Chen contributed to conceptualization, data collection, data curation, formal analysis, writing the original draft, and review and editing of the paper. Lisha Hou and Xin Xia contributed to data collection, data curation, and review and editing of the paper. Fengjuan Hu contributed to data collection, data curation. Shuyue Luo contributed to data collection, data curation. Wanyu Zhao contributed to data collection, data curation. Yan Zhang contributed to data collection, data curation. Meiling Ge contributed to data collection, data curation. Gongchang Zhang contributed to data collection, data curation. Birong Dong contributed to study conceptualization, funding acquisition, investigation, methodology, project administration, supervision, and review and editing of the paper.

\section{Availability of Data and Materials}

The datasets generated and analyzed during the current study are not publicly available due to this is a newly database which has a lot of important information and we are applying some important projects based on this. But this dataset will be available two years later and is also available now from the corresponding author on a reasonable request.

\section{Consent to publish}

Not applicable

\section{References}

1. Gustafson D, Rothenberg E, Blennow K, Steen B, Skoog I. An 18-year follow-up of overweight and risk of Alzheimer disease. Archives of internal medicine. Jul 14 2003;163(13):1524-1528.

2. Kivipelto M, Ngandu T, Fratiglioni L, et al. Obesity and vascular risk factors at midlife and the risk of dementia and Alzheimer disease. Archives of neurology. Oct 2005;62(10):1556-1560.

3. Luchsinger JA, Patel B, Tang MX, Schupf N, Mayeux R. Measures of adiposity and dementia risk in elderly persons. Archives of neurology. Mar 2007;64(3):392-398.

4. Anstey KJ, Cherbuin N, Budge M, Young J. Body mass index in midlife and late-life as a risk factor for dementia: a meta-analysis of prospective studies. Obesity reviews: an official journal of the International Association for the Study of Obesity. May 2011;12(5):e426-437. 
5. Loef $\mathrm{M}$, Walach $\mathrm{H}$. Midlife obesity and dementia: meta-analysis and adjusted forecast of dementia prevalence in the United States and China. Obesity (Silver Spring, Md.). Jan 2013;21(1):E51-55.

6. Sabia S, Kivimaki M, Shipley MJ, Marmot MG, Singh-Manoux A. Body mass index over the adult life course and cognition in late midlife: the Whitehall II Cohort Study. The American journal of clinical nutrition. Feb 2009;89(2):601-607.

7. Yoon DH, Choi SH, Yu JH, Ha JH, Ryu SH, Park DH. The relationship between visceral adiposity and cognitive performance in older adults. Age Ageing. Jul 2012;41(4):456-461.

8. Huang T, Chen Z, Shen L, Fan X, Wang K. Associations of Cognitive Function with BMI, Body Fat Mass and Visceral Fat in Young Adulthood. Medicina (Kaunas, Lithuania). May 28 2019;55(6).

9. Chiba I, Lee S, Bae S, Makino K, Shinkai Y, Shimada H. Visceral Fat Accumulation Is Associated with Mild Cognitive Impairment in Community-Dwelling Older Japanese Women. The journal of nutrition, health \& aging. 2020;24(3):352-357.

10. Moh MC, Low S, Ng TP, et al. Role of endothelium-independent vasodilation in the relationship between visceral adiposity and reduced cognitive performance in older adults with type 2 diabetes. May 2020;27(4):e12609.

11. Jagust W, Harvey D, Mungas D, Haan M. Central obesity and the aging brain. Archives of neurology. Oct 2005;62(10):1545-1548.

12. Abbatecola AM, Lattanzio F, Spazzafumo L, et al. Adiposity predicts cognitive decline in older persons with diabetes: a 2-year follow-up. PLoS One. Apr 23 2010;5(4):e10333.

13. Luchsinger JA, Biggs ML, Kizer JR, et al. Adiposity and cognitive decline in the cardiovascular health study. Neuroepidemiology. 2013;40(4):274-281.

14. Liu X, Hao Q, Yue J, et al. Sarcopenia, Obesity and Sarcopenia Obesity in Comparison: Prevalence, Metabolic Profile, and Key Differences: Results from WCHAT Study. The journal of nutrition, health \& aging. 2020/02/12 2020.

15. Liu X, Hou L, Xia X, et al. Prevalence of sarcopenia in multi ethnics adults and the association with cognitive impairment: findings from West-China health and aging trend study. Feb 17 2020;20(1):63.

16. Liu X, Hao Q, Hou L, et al. Ethnic Groups Differences in the Prevalence of Sarcopenia Using the AWGS Criteria. The journal of nutrition, health \& aging. 2020/06/01 2020;24(6):665-671.

17. Cruz-Jentoft AJ, Francesco L, Schneider SM, et al. Prevalence of and interventions for sarcopenia in ageing adults: a systematic review. Report of the International Sarcopenia Initiative (EWGSOP and IWGS). Age \& Ageing. 2014;43(6):748-759.

18. Tosato M, Marzetti E, Cesari M, et al. Measurement of muscle mass in sarcopenia: from imaging to biochemical markers. Aging clinical and experimental research. Feb 2017;29(1):19-27.

19. Cruz-Jentoft AJ, Bahat G, Bauer J, et al. Sarcopenia: revised European consensus on definition and diagnosis. Age Ageing. Jul 1 2019;48(4):601.

20. Pfeiffer E. A short portable mental status questionnaire for the assessment of organic brain deficit in elderly patients. Journal of the American Geriatrics Society. Oct 1975;23(10):433-441.

21. Lim PP, Ng LL, Chiam PC, Ong PS, Ngui FT, Sahadevan S. Validation and comparison of three brief depression scales in an elderly Chinese population. International journal of geriatric psychiatry. Sep 2000;15(9):824-830.

22. Tsai PS, Wang SY, Wang MY, et al. Psychometric evaluation of the Chinese version of the Pittsburgh Sleep Quality Index (CPSQI) in primary insomnia and control subjects. Quality of life research: an international journal of quality of life aspects of treatment, care and rehabilitation. Oct 2005;14(8):1943-1952. 
23. James WP. International Association for the Study of Obesity and China. Obesity reviews: an official journal of the International Association for the Study of Obesity. Mar 2008;9 Suppl 1:2-3.

24. Han C, Jo SA, Seo JA, et al. Adiposity parameters and cognitive function in the elderly: application of "Jolly Fat" hypothesis to cognition. Archives of gerontology and geriatrics. Sep-Oct 2009;49(2):e133-e138.

25. Jia W, Lu J, Xiang K, Bao Y, Lu H, Chen L. [Evaluation of abdominal visceral obesity from anthropometric parameters using receiver operating characteristic curves]. Zhonghua liu xing bing xue za zhi = Zhonghua liuxingbingxue zazhi. Feb 2002;23(1):20-23.

26. Nagano M, Sasaki H, Kumagai S. [The cutoff point of visceral fat area as a goal for improving risk factors of arteriosclerosis in patients with glucose intolerance]. Nihon rinsho. Japanese journal of clinical medicine. Feb 2005;63 Suppl 2:417-420.

27. New criteria for 'obesity disease' in Japan. Circulation journal: official journal of the Japanese Circulation Society. Nov 2002;66(11):987-992.

28. Pais R, Ruano L, O PC. Global Cognitive Impairment Prevalence and Incidence in Community Dwelling Older Adults-A Systematic Review. Oct 27 2020;5(4).

29. Cao Q, Tan CC, Xu W, et al. The Prevalence of Dementia: A Systematic Review and Meta-Analysis. Journal of Alzheimer's disease: JAD. 2020;73(3):1157-1166.

30. Nasios G, Bakirtzis C, Messinis L. Cognitive Impairment and Brain Reorganization in MS: Underlying Mechanisms and the Role of Neurorehabilitation. Frontiers in neurology. 2020;11:147.

31. Yaffe K, Barnes D, Lindquist K, et al. Endogenous sex hormone levels and risk of cognitive decline in an older biracial cohort. Neurobiology of aging. Feb 2007;28(2):171-178.

32. Signore AP, Zhang F, Weng Z, Gao Y, Chen J. Leptin neuroprotection in the CNS: mechanisms and therapeutic potentials. Journal of neurochemistry. Sep 2008;106(5):1977-1990.

33. Lieb W, Beiser AS, Vasan RS, et al. Association of plasma leptin levels with incident Alzheimer disease and MRI measures of brain aging. Jama. Dec 16 2009;302(23):2565-2572.

34. Zhang T, Yan R, Chen Q, et al. Body mass index, waist-to-hip ratio and cognitive function among Chinese elderly: a cross-sectional study. BMJ open. Oct 18 2018;8(10):e022055.

35. Rodríguez-Fernández JM, Danies E, Martínez-Ortega J, Chen WC. Cognitive Decline, Body Mass Index, and Waist Circumference in Community-Dwelling Elderly Participants. Journal of geriatric psychiatry and neurology. Mar 2017;30(2):67-76.

36. Moh MC, Low S, Ng TP, et al. Association of traditional and novel measures of central obesity with cognitive performance in older multi-ethnic Asians with type 2 diabetes. Apr 2020;10(2):e12352.

\section{Supplementary Files}

This is a list of supplementary files associated with this preprint. Click to download.

- supplementarymaterial.docx 